\title{
Opioidergic inhibition of luteinising hormone and prolactin release changes during pregnancy in pony mares
}

\author{
C Aurich, J E Aurich ${ }^{1}$ and $\mathbf{N}$ Parvizi $^{2}$ \\ Centre for Artificial Insemination and Embryo Transfer, University of Veterinary Sciences, Veterinärplatz 1, 1210 Vienna, Austria \\ ${ }^{1}$ Clinic for Obstetrics, Gynaecology and Andrology, University of Veterinary Sciences, 1210 Vienna, Austria \\ ${ }^{2}$ Institute for Animal Husbandry and Animal Behaviour (FAL), 31535 Neustadt-Mariensee, Germany \\ (Requests for offprints should be addressed to C Aurich; Email: christine.aurich@vu-wien.ac.at)
}

\begin{abstract}
In equine species, luteinising hormone (LH) and prolactin (PRL) release are reduced throughout pregnancy but increase at foaling. The present experiments were designed to study a possible opioidergic regulation of $\mathrm{LH}$ and PRL release in pregnant Shetland mares $(n=6)$. At various stages of pregnancy (days $26 \cdot 4 \pm 0 \cdot 6, \quad 75 \cdot 4 \pm 5 \cdot 4$, $171 \cdot 8 \pm 2 \cdot 4,226 \cdot 2 \pm 4 \cdot 8,282 \cdot 7 \pm 3 \cdot 4$ and $319 \cdot 8 \pm 2 \cdot 1)$, mares were injected with the opioid antagonist naloxone $(0.5 \mathrm{mg} / \mathrm{kg}$ body weight $)$ and saline. The two treatments were always separated by 2 days, and mares served as their own controls. Two hours after being given naloxone and saline, mares were given the gonadotrophin-releasing hormone $(\mathrm{GnRH})$ analogue buserelin $(5 \mu \mathrm{g}$ per animal). The naloxone experiment was repeated at 2 days after foaling. Blood for the determination of LH and PRL was withdrawn at $15 \mathrm{~min}$ intervals for $240 \mathrm{~min}$, and naloxone or saline was injected after $60 \mathrm{~min}$. Naloxone induced
\end{abstract}

significant $(P<0 \cdot 05) \mathrm{LH}$ release on days 172,226 and 283 of pregnancy but not on days 26, 76 and 320 and 2 days after foaling. Buserelin caused a significant $(P<0 \cdot 05)$ increase in plasma LH concentrations on days 172, 226, 282 and 320 of pregnancy. The experiments indicate that endogenous opioids are involved in the inhibition of $\mathrm{LH}$ release during the second half of pregnancy in equine species. The deactivation of opioid effects on $\mathrm{LH}$ release might be a prerequisite for the onset of ovarian activity postpartum. Plasma PRL concentrations increased significantly $(P<0 \cdot 05)$ after naloxone administration on days 226 , 282 and 320 of pregnancy. The naloxone-induced PRL release was most pronounced towards term, indicating an increase in the naloxone-releasable pool and/or the absence of other PRL-release inhibitory mechanisms.

Journal of Endocrinology (2001) 169, 511-518

\section{Introduction}

In equine species, as in other species, release of luteinising hormone ( $\mathrm{LH}$ ) and prolactin (PRL) from the anterior pituitary is affected by pregnancy. LH release is reduced in pregnant mares (Nett et al. 1975b) but increases after foaling (Nett et al. 1975a, Noden et al. 1978), leading to a fertile ovulation within 10 days postpartum in most mares. PRL release is low during most of pregnancy, increases shortly antepartum and is elevated for at least 2 weeks after foaling (Nett et al. 1975a, Lothrop et al. 1987, Worthy et al. 1987). The increase in PRL concentration is a prerequisite for normal galactogenesis (Ireland et al. 1991).

In non-pregnant mares, endogenous opioids inhibit LH release during the luteal, but not the follicular, phase (Behrens et al. 1993) and during the anovulatory season (Aurich et al. 1994). Opioids influence LH release via the secretion of gonadotrophin-releasing hormone $(\mathrm{GnRH})$ from the hypothalamus (Parvizi \& Ellendorff 1980, Alexander et al. 2000). The opioidergic inhibition of $\mathrm{GnRH} / \mathrm{LH}$ release contributes to seasonal anoestrus in equine species, and transition into the breeding season coincides with a switch from a continuous opioidergic inhibition to an intermittent, cycle-dependent blockade of LH release (Aurich et al. 1994). In cyclic mares, the opioidergic inhibition of $\mathrm{LH}$ secretion is activated by a sequence of oestrogen and progesterone influence characteristic of the oestrous cycle. In seasonal anoestrous mares, the opioidergic inhibition of $\mathrm{LH}$ release can be stimulated by a prolonged period of oestrogen exposure or independently of ovarian factors (Aurich et al. 1994, 1995, 1997). Opioids inhibit PRL secretion in steroid-treated (Aurich et al. 1995) and melatonin-treated (Aurich et al. 1997) ovariectomised mares but not in non-pregnant, ovaryintact mares. In the non-pregnant mare, PRL release is primarily inhibited by dopamine (Aurich et al. 2000), and the physiological relevance of opioids for the regulation of PRL release remains to be established.

In equine species, opioidergic regulation of $\mathrm{LH}$ and PRL secretion during pregnancy has not been investigated. The physiological duration of pregnancy in the mare is between 315 and 365 days. Progesterone and 
oestrogen release, which could affect LH and PRL regulatory opioidergic pathways, change throughout pregnancy. Progesterone is secreted exclusively from the primary corpus luteum until day 40. Under the influence of equine chorionic gonadotrophin (eCG), secondary corpora lutea are formed after day 40 of pregnancy. After day 60 , gestagens are also produced by the placenta, and from day 150 onwards, the placenta is the only source of gestagens in the pregnant mare (Holtan et al. 1991). High oestrogen concentrations in the blood of pregnant mares are found from the 4th to the 9th month of gestation (Nett et al. 1973).

The present experiment was designed to study a possible opioidergic regulation of $\mathrm{LH}$ and PRL release in pregnant pony mares. The effects of the opioid antagonist naloxone on LH and PRL concentrations in plasma at different stages of pregnancy were determined. In a preliminary study, the effects of repeated injection of the $\mathrm{GnRH}$ analogue buserelin, given at different intervals, on LH release were studied.

\section{Materials and Methods}

\section{Animals}

Experiments were performed according to Austrian federal animal welfare legislation. In the preliminary study, Shetland mares $(n=15)$ were used. They were between 3 and 15 years of age (mean age 9 years) and weights were between 180 and $250 \mathrm{~kg}$. The animals used in the main study were Shetland mares $(n=7)$ aged $9 \cdot 9 \pm 2 \cdot 6$ years (S.D.) and weighing $165 \pm 7 \mathrm{~kg}$ (S.D.). Ponies were kept as a single group in a spacious stable and had permanent access to a pasture. In addition to having access to pasture, they were fed hay and mineral supplements; water was freely available. All mares were mated with a Shetland stallion every other day during oestrus. Oestrus was determined by daily checking for oestrous behaviour with the stallion and by daily determination of plasma progesterone concentrations. Because of the size of the animals, ovarian function was not determined by repeated transrectal palpation. The first day on which plasma progesterone concentrations exceeded $3.4 \mathrm{nmol} / 1$ was defined as day one after ovulation (i.e. day 1 of pregnancy). Six of the seven mares became pregnant between 23 June and 30 July. Pregnancy was confirmed by transrectal ultrasonography on days 18 and 45 after mating. The six pregnant mares were included in the study and foaled between 18 May and 14 June the following year. The average gestation length was $329 \cdot 8 \pm 8 \cdot 5$ days (s.D.).

\section{Experimental procedures}

In order to determine the interval between repetitive LH-releasing treatments, in a preliminary experiment
15 mares were injected twice with $5 \mu \mathrm{g}$ of the GnRH agonist buserelin (Receptal; Hoechst, Unterschleissheim, Germany). The intervals between the two buserelin injections were $2(n=5), 4(n=5)$ and 6 days $(n=5)$. Blood for the determination of LH concentrations was withdrawn at 15 min intervals from 45 min before to $60 \mathrm{~min}$ after the buserelin injections. Experiments were performed in February and all mares were seasonally acyclic.

The main experiments were performed on days $26 \cdot 4 \pm 0 \cdot 6,75 \cdot 4 \pm 5 \cdot 4,171 \cdot 8 \pm 2 \cdot 4,226 \cdot 2 \pm 4 \cdot 8,282 \cdot 7 \pm$ $3 \cdot 4$ and $319 \cdot 8 \pm 2 \cdot 1$ of pregnancy and 2 days after foaling. All experiments were begun between 0800 and $0900 \mathrm{~h}$. During blood sampling, the ponies remained in their stable. An indwelling catheter (Braun, Melsungen, Germany) was placed in one jugular vein 15 min before the first blood sample was withdrawn. Blood for the determination of LH and PRL was withdrawn at $15 \mathrm{~min}$ intervals for $240 \mathrm{~min}$. In all experiments during pregnancy, after $60 \mathrm{~min}$ of sampling, $80 \mathrm{mg}$ naloxonehydrochloride (Sigma Chemicals, Deisenhofen, Germany) per animal or $6 \mathrm{ml}$ saline was injected intravascularly via the catheter. Naloxone was freshly dissolved in $6 \mathrm{ml}$ saline and was filter-sterilized immediately before the injection. The dose of naloxone corresponded to $0.5 \mathrm{mg} / \mathrm{kg}$ body weight. Immediately after withdrawal, blood samples were centrifuged for $20 \mathrm{~min}$ at $1000 \mathrm{~g}$, and plasma was frozen at $-20{ }^{\circ} \mathrm{C}$ until hormone analysis. Two hours after the injection of naloxone or saline, $5 \mu \mathrm{g}$ of the GnRH analogue buserelin was administered to enable investigation of pituitary responsiveness to GnRH. Blood samples were collected for another $60 \mathrm{~min}$, i.e. until $180 \mathrm{~min}$ after naloxone or saline administration. Plasma progesterone concentrations were measured in the first blood sample taken on each day. In the experiment 2 days after foaling, blood samples were taken for $240 \mathrm{~min}$, all animals received naloxone $120 \mathrm{~min}$ after the first blood sample was withdrawn, and no buserelin was given.

In all experiments, mares were used as their own controls and were treated with naloxone and saline. The interval between the two treatments in the same animal was 2 days. The order of treatments was randomised, with half of the animals receiving naloxone first and half receiving saline injections first. Two days after foaling, no control experiment was performed. LH and PRL release during the $2 \mathrm{~h}$ before and after injection of naloxone was compared. This procedure was chosen because of the rapidly changing hormone environments in postpartum mares. In early postpartum mares, data from control and naloxone experiments performed at 2 day intervals would not have been comparable.

\section{Hormone assays}

Concentrations of LH, PRL and progesterone in plasma were measured by radioimmunoassay (RIA) as described 
previously (Behrens et al. 1993). The assay for LH utilised equine LH (Biogenesis, Poole, Dorset, UK) as the standard and for iodination, and an antibody raised in rabbits against equine $\mathrm{LH}$ (A 543; Biogenesis). The intra- and interassay coefficients of variation were $5 \cdot 8$ and $18 \cdot 1 \%$ respectively. The minimal detectable concentration was $0.5 \mu \mathrm{g} / 1$; the cross-reactivity with follicle-stimulating hormone was $2 \cdot 8 \%$ and that with equine chorionic gonadotrophin was $23 \%$.

The RIA for PRL was performed with an antiserum raised in rabbits against equine PRL (AFP 361687; Dr A F Parlow, Harbor-UCLA Medical Center, Torrance, CA, USA). The intra- and interassay coefficients of variation were $4 \cdot 1 \%$ and $10 \cdot 3 \%$ respectively, the minimal detectable concentration was $0 \cdot 25 \mu \mathrm{g} / 1$, and the crossreactivity of the antibody with equine growth hormone (AFP 7424C, Dr A F Parlow) was $<0 \cdot 1 \%$ (Aurich et al. 1995). Progesterone was determined by RIA after extraction from plasma with $n$-hexane as described previously (Behrens et al. 1993). The intra- and interassay coefficients of variation were 4.5 and $7.9 \%$ respectively, and the minimal detectable concentration was $0 \cdot 16 \mathrm{nmol} / \mathrm{l}$.

\section{Statistical analysis}

In the preliminary experiment, basal LH concentrations were calculated as the means of the 4 pre-buserelin values. LH release in response to buserelin was calculated as the area under the curve (AUC; $\mathrm{ng} / \mathrm{ml}$ per min) for the time period 0-60 min after the injection of buserelin $\left[\Sigma\left(\mathrm{x}_{\mathrm{n}}+\right.\right.$ $\left.\left.\mathrm{x}_{\mathrm{n}+1}\right) / 2 \times 15\right)$ ] taking into account the 15 min sampling interval. Both basal LH concentrations and LH release after buserelin were compared by using the Wilcoxon matched pairs ranked sum test. In the main experiment, PRL and LH release in individual mares was calculated as the AUC ( $\mathrm{ng} / \mathrm{ml}$ per $\mathrm{min}$ ) for the time period from 0-120 min after the injection of naloxone or saline. The pretreatment baseline, calculated as the mean of 5 values before the naloxone or saline injections, was subtracted from the value for each post-treatment sample. Statistical comparisons were made with the SPSS/PC+ statistics package (Norusis 1988). Because no asumption was made about the distribution of data, non-parametric tests were used. Naloxone and respective saline experiments in pregnant mares were compared by using the Wilcoxon matched pairs ranked sum test. Basal hormone concentrations in the same animals at different times, LH and PRL concentrations in mares 2 days postpartum before and after naloxone injections (the AUCs for $2 \mathrm{~h}$ before vs $2 \mathrm{~h}$ after naloxone injection) and $\mathrm{LH}$ and PRL concentrations before and after buserelin injections (the AUCs for $1 \mathrm{~h}$ before vs $1 \mathrm{~h}$ after buserelin injection) were compared by using Friedman's two-way ANOVA, taking into account the sequential nature of the data. For comparisons of basal hormone concentrations, data from control experiments were used. The data presented are means \pm s.E.M. values.

\section{Results}

\section{$L H$ release after buserelin given at different intervals}

When mares were treated twice with buserelin at 2, 4 or 6 day intervals, basal LH concentrations before the first and the second treatments were not significantly different. LH release in response to the second injection did not differ significantly from the LH response to the first buserelin injection (see Fig. 1). LH release data (the AUC) for the time period $0-45 \mathrm{~min}$ after the first and second buserelin injection were as follows: $27 \cdot 0 \pm 4 \cdot 1$ and $26 \cdot 8 \pm 4 \cdot 2 \mathrm{ng} / \mathrm{ml}$ per $\min$ for the 2 day interval; $28 \cdot 1 \pm 4 \cdot 8$ and $30.3 \pm 3.2 \mathrm{ng} / \mathrm{ml}$ per min for the 4 day interval; and $26 \cdot 6 \pm 4 \cdot 4$. and $29 \cdot 5 \pm 3 \cdot 8 \mathrm{ng} / \mathrm{ml}$ per min for the 6 day interval.

\section{Progesterone}

Plasma progesterone concentrations on days 26, 76, 172, 226,283 and 320 of pregnancy were $44 \cdot 4 \pm 1 \cdot 7$, $36 \cdot 7 \pm 4 \cdot 5, \quad 32 \cdot 3 \pm 10 \cdot 3, \quad 14 \cdot 4 \pm 0 \cdot 9, \quad 17 \cdot 2 \pm 0 \cdot 8$ and $17 \cdot 1 \pm 1 \cdot 1 \mathrm{nmol} / 1$ respectively.

\section{Basal LH and PRL concentrations}

Mean basal LH concentrations in plasma reached a maximum on day 76 of gestation $(P<0 \cdot 05$ vs all other times) and were significantly $(P<0 \cdot 05)$ higher on day 172 of gestation than on days 26, 226, 283 and 320 of pregnancy and 2 days after foaling. Plasma PRL concentrations reached a nadir on days 172 and 226 of gestation $(P<0 \cdot 05$ vs all other times) and increased significantly at the end of gestation and further after foaling (day 320 and 2 days postpartum vs all other times, $P<0 \cdot 05$; see Table 1 ).

\section{$L H$ release in response to naloxone and buserelin}

The opioid antagonist naloxone induced a significant $(P<0.05$ vs controls) LH release on days 172, 226 and 282 of pregnancy. On day 320, LH release after naloxone tended to increase but the difference with respect to the control experiment did not reach statistical significance. Treatment with naloxone did not influence $\mathrm{LH}$ release on days 26 and 76 of pregnancy and 2 days after foaling (see Figs 2 and 3). LH release in response to naloxone (the AUC) was $225.9 \pm 94.0 \mathrm{ng} / \mathrm{ml}$ per min on day 172 , $196 \cdot 0 \pm 37 \cdot 0 \mathrm{ng} / \mathrm{ml}$ per $\min$ on day $226,177 \cdot 0 \pm$ $41.1 \mathrm{ng} / \mathrm{ml}$ per min on day 282 and $108.9 \pm 52.9 \mathrm{ng} / \mathrm{ml}$ per min on day 320 of pregnancy. The respective values for control experiments were $56 \cdot 7 \pm 46 \cdot 5,46 \cdot 5 \pm 8 \cdot 7$, $47 \cdot 4 \pm 23 \cdot 3$ and $56 \cdot 4 \pm 20 \cdot 4 \mathrm{ng} / \mathrm{ml}$ per min. The GnRH agonist buserelin caused a significant $(P<0 \cdot 05)$ increase in plasma LH concentrations on days 172, 226, 282 and 320 but not on days 26 and 76 of pregnancy, irrespective of the pretreatment with either naloxone or saline (see Fig. 2). 

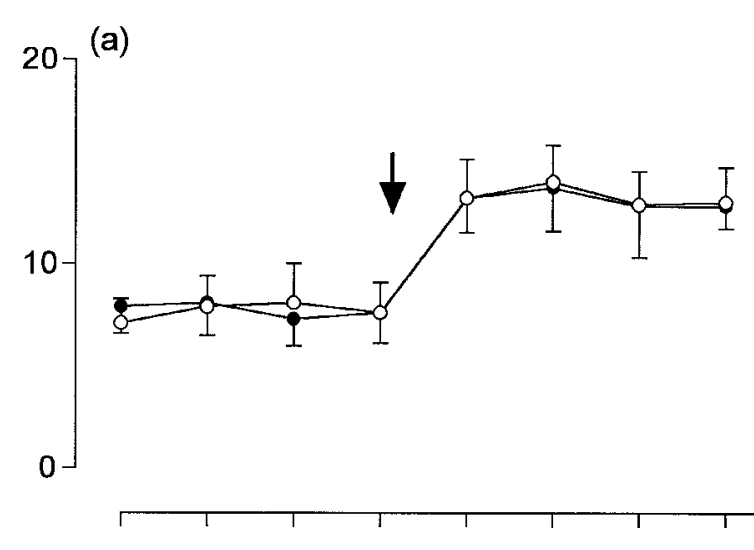

(b)
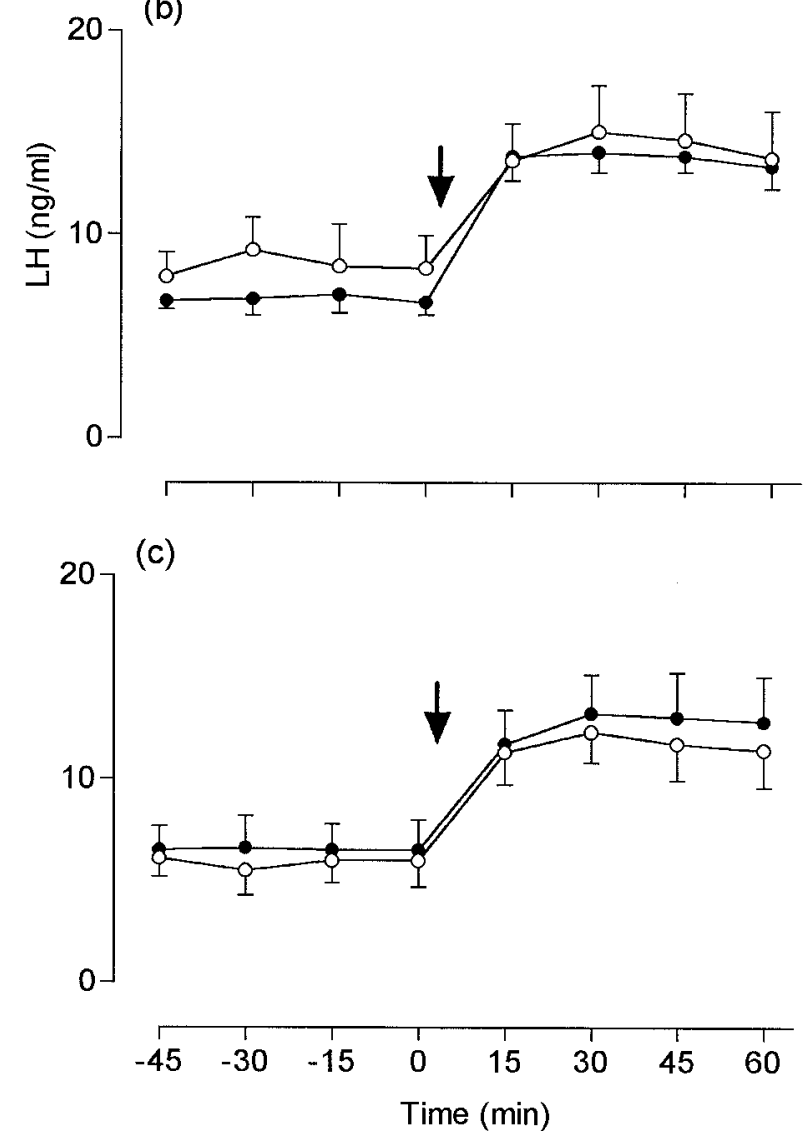

Figure 1 Concentrations of $\mathrm{LH}$ in plasma before and after two injections of buserelin (arrow; $5 \mu$ g, i.v.; $\bigcirc$ first injection, - second injection) given at a 2 day (a), 4 day (b) or 6 day (c) interval. There were no significant differences between first and second treatments.

\section{$P R L$ release in response to naloxone and buserelin}

On days 226, 282 and 320 of pregnancy, PRL concentrations were elevated significantly after the injection of naloxone. The naloxone-induced PRL release increased
Table 1 Basal plasma LH and PRL concentrations $(\mathrm{ng} / \mathrm{ml})$ in mares at different times of pregnancy and at 2 days after foaling; values are means \pm S.E.M.
LH

Day (month)

$26 \cdot 4 \pm 0 \cdot 6$ (Aug.)

$75 \cdot 4 \pm 5 \cdot 4$ (Sept./Oct.)

$171 \cdot 8 \pm 2 \cdot 4$ (Dec./Jan.)

$226 \cdot 2 \pm 4 \cdot 8$ (Feb./Mar.)

$282 \cdot 7 \pm 3 \cdot 4$ (Mar./Apr.)

$319 \cdot 8 \pm 2 \cdot 1$ (May/Jun.)

Day 2 postpartum (May/Jun.)
$3 \cdot 1 \pm 0 \cdot 6^{\mathrm{a}}$

$63 \cdot 3 \pm 8 \cdot 6^{\mathrm{b}}$

$4 \cdot 1 \pm 0 \cdot 5^{\mathrm{c}}$

$2 \cdot 1 \pm 0 \cdot 5^{\mathrm{a}}$

$1 \cdot 8 \pm 0 \cdot 3^{\mathrm{a}}$

$1 \cdot 7 \pm 0 \cdot 3^{\mathrm{a}}$

$2 \cdot 4 \pm 0 \cdot 5^{\mathrm{a}}$
PRL

$2 \cdot 0 \pm 0 \cdot 4^{\mathrm{a}}$

$1 \cdot 6 \pm 0 \cdot 5^{\mathrm{a}}$

$0 \cdot 4 \pm 0 \cdot 1^{b}$

$0 \cdot 5 \pm 0 \cdot 1^{b}$

$1 \cdot 4 \pm 0 \cdot 3^{\mathrm{a}}$

$4 \cdot 1 \pm 2 \cdot 0^{\mathrm{c}}$

$8 \cdot 4 \pm 3 \cdot 4^{\mathrm{c}}$
${ }^{a-c}$ Values with different superscript letters in the same column are significantly different.

from day 226 to day 282 and further to day 320 (day 226 vs day $320, P<0 \cdot 05$; see Fig. 4). No further changes were found in response to buserelin. Neither naloxone nor buserelin caused any changes in plasma PRL concentrations on days 26,76 and 172 of pregnancy. PRL release in response to naloxone (the AUC) was $237 \cdot 9 \pm 79 \cdot 0 \mathrm{ng} /$ $\mathrm{ml}$ per min on day $226,575 \cdot 5 \pm 209 \cdot 4 \mathrm{ng} / \mathrm{ml}$ per min on day 282 and $1498 \cdot 0 \pm 574 \cdot 1 \mathrm{ng} / \mathrm{ml}$ per min on day 320 of pregnancy. The respective values for control experiments were $12 \cdot 5 \pm 12 \cdot 6,1 \cdot 4 \pm 31 \cdot 7$ and $-47 \cdot 7 \pm 36 \cdot 6 \mathrm{ng} / \mathrm{ml}$ per min. Two days after foaling, naloxone no longer affected plasma PRL concentrations (see Fig. 3).

\section{Discussion}

The present experiments indicate that endogenous opioids are involved in the inhibition of $\mathrm{LH}$ release in equine mares during the second half of pregnancy but not in early pregnant mares and not during the last days preceding parturition.

The preliminary study was performed to investigate if treatments could be performed at 2 day intervals without the first buserelin injection influencing the response to the second injection. The data showed that this interval is sufficient, at least when a low and sub-therapeutic buserelin dose is used, as in our study.

The opioid antagonist naloxone did not affect $\mathrm{LH}$ release on days 26 and 76 after ovulation in pregnant mares. This is in contrast to cyclic mares, in which opioids inhibit LH release during the luteal phase (Behrens et al. 1993). In pregnant mares less than 2 weeks later, naloxone no longer releases LH, although the oestrogenprogesterone environment is similar to that of dioestrus. The disappearence of naloxone-induced LH release could be explained either by deactivation of the opioidergic system or by a reduced pituitary responsiveness to $\mathrm{GnRH}$ in early pregnancy. The later interpretation is supported by the facts that opioids affect LH release indirectly by inhibiting GnRH release (Parvizi \& Ellendorff 1980, 
(a) Day 26 of pregnancy

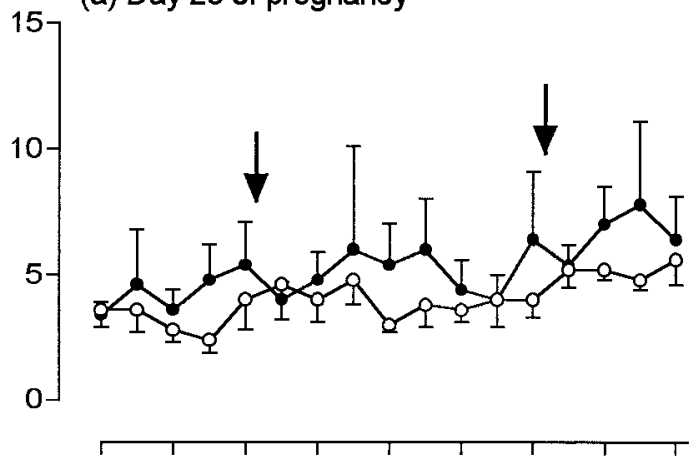

(c) Day 172 of pregnancy

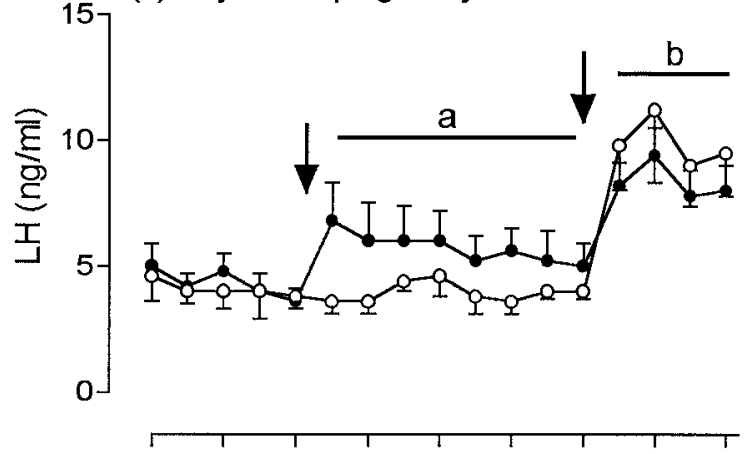

(e) Day 282 of pregnancy

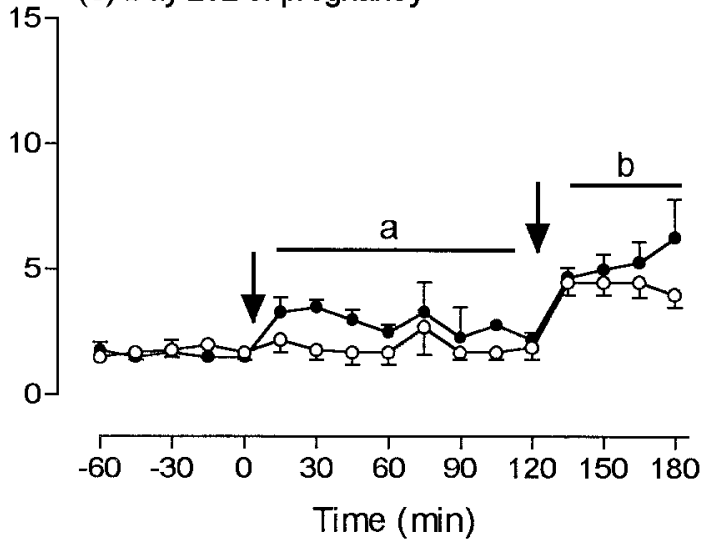

(b) Day 76 of pregnancy

$\left.\begin{array}{r}90 \\ 80- \\ 70- \\ 60- \\ 50- \\ 40- \\ 30- \\ 20- \\ 10- \\ 0\end{array}\right]$

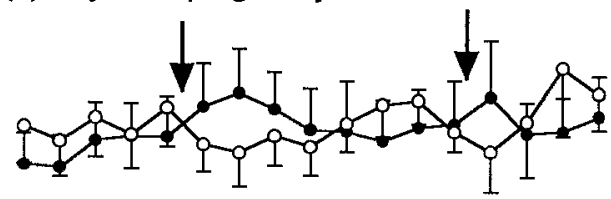

(d) Day 226 of pregnancy
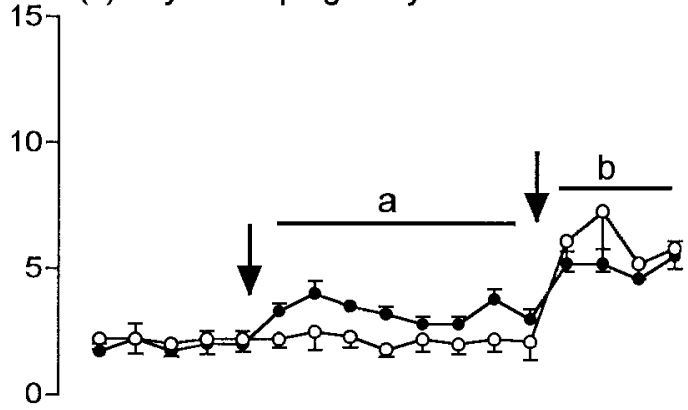

(f) Day 320 of pregnancy

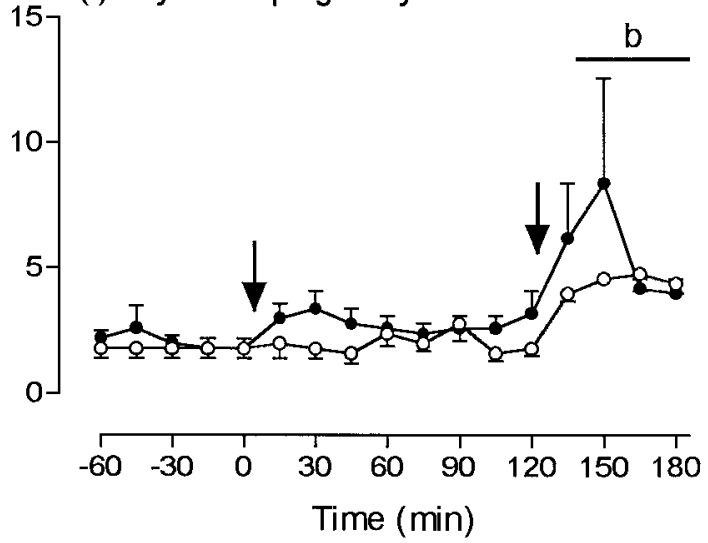

Figure 2 Concentrations of LH in plasma of pregnant mares $(n=6)$ before and after injection of naloxone $(\bullet)$ or saline $(\bigcirc$; time, $0 \mathrm{~min}$ ) and buserelin (time, $120 \mathrm{~min}$ ) (arrows); values are means \pm S.E.M. a There is a significant difference between naloxone treatment and control treatment $(P<0.05$; AUC for the time period from 0 to 120 min after naloxone or saline injections). $\underline{b} \mathrm{LH}$ values before and after the injection of buserelin are significantly different $(P<0 \cdot 05)$.

Alexander et al. 2000) and that buserelin did not cause any LH release on day 26 of pregnancy.

High LH concentrations around day 76 of pregnancy consist mainly of eCG, which reaches maximal concen- trations in plasma towards day 60 (Rowlands 1949, Allen 1975). Equine CG has evolved by expression of the LH gene in the placenta; however, LH and CG are considered as different hormones (Stewart \& Allen 1995). The 


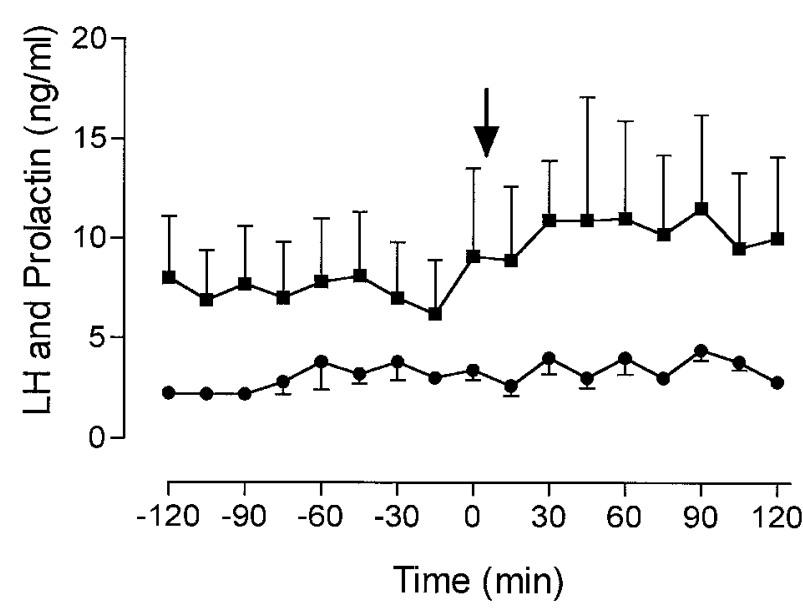

Figure 3 Concentrations of $\mathrm{LH}(\boldsymbol{O})$ and prolactin $(\boldsymbol{\square})$ in the plasma of mares 2 days after foaling, before and after the injection of naloxone (arrow); values are means \pm S.E.M. Naloxone had no significant effect on $\mathrm{LH}$ and PRL release.

antiserum used in our study did not sufficiently differentiate between LH and CG, and LH concentrations at day 76 of pregnancy have to be interpreted as LH immunoreactivity. The CG concentrations were not affected by naloxone. Because eCG release is not regulated via $\mathrm{GnRH}$ (Thompson et al. 1982), a GnRH-mediated effect of naloxone was not to be expected. In addition, there is no direct opioidergic regulation of CG release from the endometrial cups. An effect of naloxone on pituitary LH release at that stage of pregnancy cannot be excluded and could have been masked by the high concentrations of eCG.

After the eCG phase, opioids inhibit LH release, indicating that opioidergic mechanisms contribute to the reduction in LH secretion during pregnancy. The seasonal increase in mean plasma $\mathrm{LH}$ concentrations that has been demonstrated in cyclic mares during spring and summer (Turner et al. 1979) did not occur in pregnant animals. The opioid inhibition of LH release was markedly reduced during the last days before foaling, and no opioidergic inhibition of LH release existed 2 days after foaling. This might be a prerequisite for the early onset of ovarian activity after parturition in the mare. In pigs and beef cattle, lactation is accompanied by a period of anoestrus. Endogenous opioids, released in response to the suckling stimulus, inhibit gonadotrophin release in these species (Whisnant et al. 1986, Armstrong et al. 1988). In contrast, in the mare, lactational anoestrus as a physiological condition does not exist and suckling does not induce an opioid-mediated suppression of LH release.

The opioidergic regulation of GnRH/LH release during pregnancy in equine species differs from that in the pig. In sows, naloxone treatment induces a short-term $\mathrm{LH}$ release on day 40 but not on day 70 of pregnancy
(Szafranska et al. 1994). LH regulatory opioidergic pathways are influenced by gonadal steroids. In the pig, progesterone is secreted from the corpus luteum throughout pregnancy, whereas in the horse during the second half of pregnancy, gestagens in the maternal blood originate in the placenta. Different gestagen patterns may explain, in part, why opioid effects on LH release differ in pigs and equine species.

Plasma PRL concentrations were low throughout pregnancy. A further reduction during winter must be considered as a seasonal variation, which has been described previously in non-pregnant mares (Johnson 1986). An opioidergic inhibition of PRL release was not detectable before day 226 of pregnancy. The amount of PRL released in response to naloxone increased continuously thereafter. An opioid-mediated inhibition of PRL release at the end of pregnancy has also been demonstrated in rats. The stimulatory effect of naloxone on PRL release was negatively correlated with progesterone levels and reached a maximum after prepartum luteolysis. In addition to a fall in progesterone levels, an increase in circulating oestrogens may contribute to the activation of a PRL-inhibitory opioidergic pathway (Soaje \& Deis 1994, 1997). Progesterone stimulates dopamine release into hypophyseal portal blood (Cramer et al. 1979). In the prepartum rat, opioids may thus limit the increase in PRL induced by the fall in progesterone (Soaje \& Deis 1994, 1997). Although, in equine species, naloxone induces a release of PRL in the presence of still-high gestagen concentrations, it can be speculated that changes in the oestrogen and gestagen profiles in mares during pregnancy cause a decrease in the dopaminergic inhibition of PRL release, and that opioids prevent a release of PRL after reduction of the dopaminergic blockade.

Naloxone-inducible PRL release does not exist in intact, non-pregnant mares but can be activated by oestradiol-progesterone and melatonin treatment in ovariectomised mares (Aurich et al. 1994, 1997). Thus, pregnancy is the only reproductive state in which opioids inhibit PRL secretion in non-pretreated mares. The dopaminergic inhibition is possibly not strong enough to overcome the naloxone-induced stimulation of PRL release. Moreover, the naloxone-induced PRL release increases markedly towards term, indicating a diminishing dopaminergic inhibition and an increase in the naloxonereleasable PRL pool. Two days after foaling, plasma PRL concentrations were no longer inhibited by opioids and were significantly higher than at any stage of pregnancy. The loss of an opioidergic inhibition of PRL release with the end of pregnancy could explain this marked increase in plasma PRL concentrations after foaling.

In conclusion, the results of this study provide new insights into the neuromodulatory regulation of LH and PRL release in pregnant mares. Opioids inhibit $\mathrm{GnRH} / \mathrm{LH}$ release during the second half of pregnancy but not during early pregnancy in the mare. A deactivation 
(a) Day 26 of pregnancy

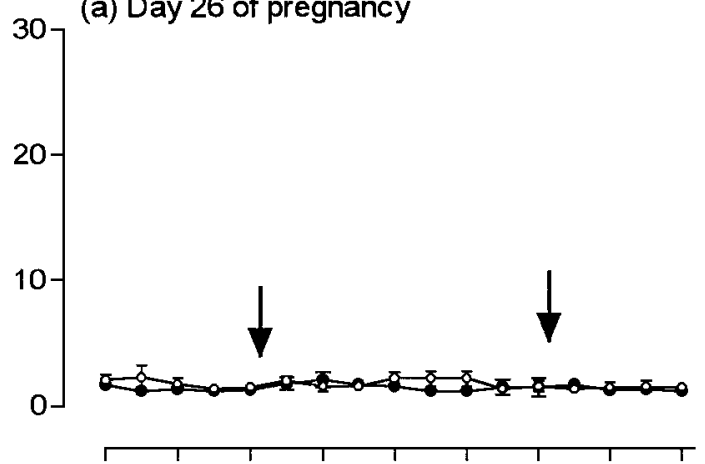

(c) Day 172 of pregnancy

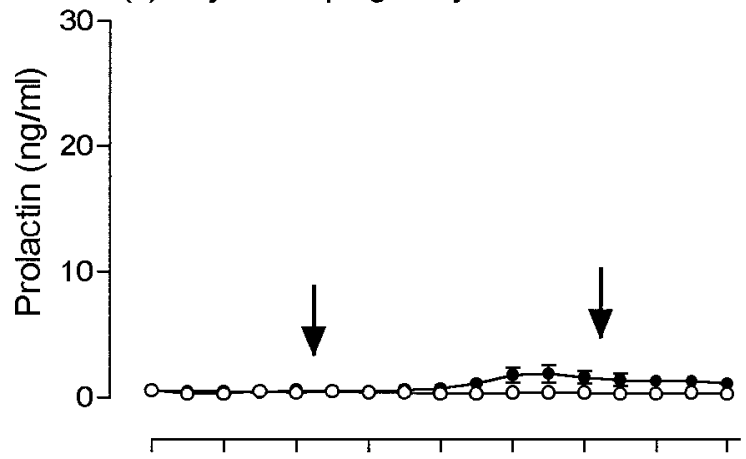

(e) Day 282 of pregnancy

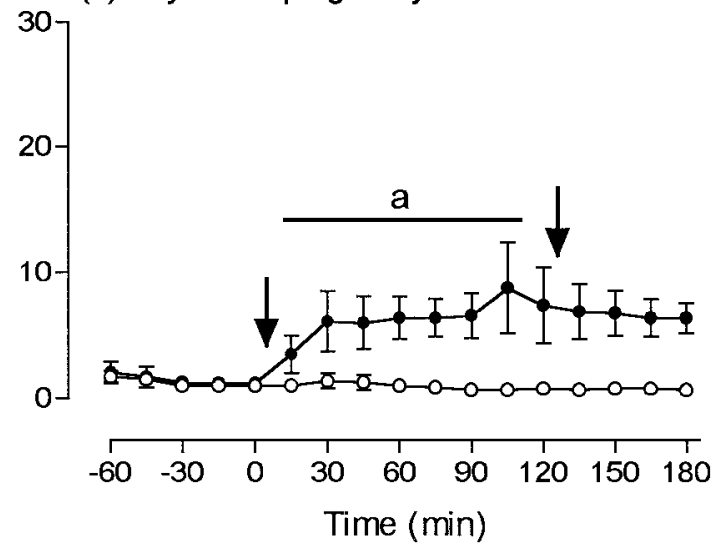

(b) Day 76 of pregnancy
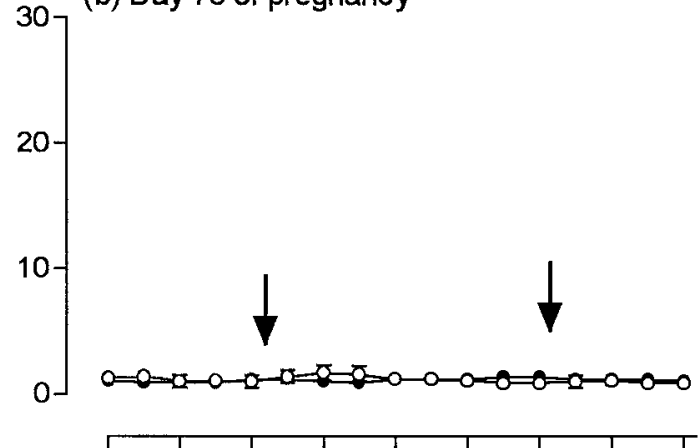

(d) Day 226 of pregnancy

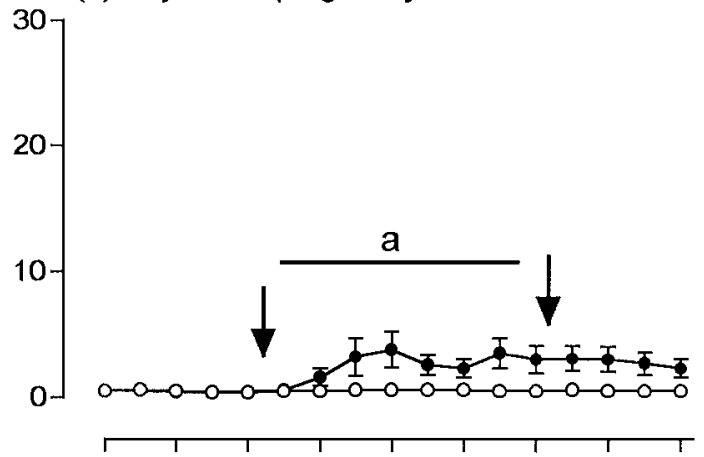

(f) Day 320 of pregnancy

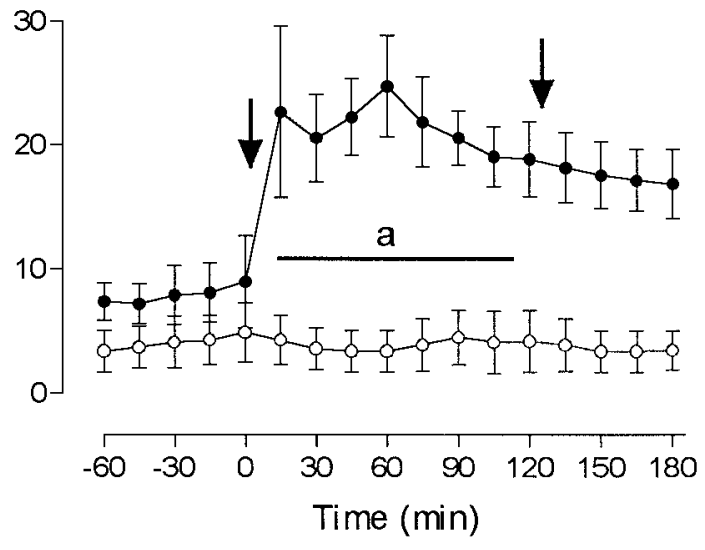

Figure 4 Concentrations of prolactin in the plasma of pregnant mares $(n=6)$ before and after the injection of naloxone $(\bullet)$ or saline $(\bigcirc$; time, $0 \mathrm{~min}$ ) and buserelin (time, $120 \mathrm{~min}$ ) (arrows); values are means \pm S.E.M. (a) There is a significant difference between naloxone treatment and control treatment $(P<0 \cdot 05$; AUC for the time period from 0 to 120 min after naloxone or saline injection; bar a).

of the opioidergic inhibition of LH release shortly before foaling might be a prerequisite for the early onset of follicular growth postpartum. In addition to LH release, PRL release is inhibited during the later stages of pregnancy, and the amount of PRL released in response to the opioid antagonist naloxone increases towards term.

\section{Acknowledgements}

The authors are grateful to the Deutsche Forschungsgemeinschaft for financial support, to Dr A F Parlow, Harbor-UCLA Medical Center, Torrance, California, USA, for reagents used in the PRL RIA, and to R Wittig, M Müller and K von Kittlitz for technical assistance. 


\section{References}

Alexander SL, Irvine CHG, Shand N \& Turner J 2000 The role of endogenous opioids in the ovulatory LH surge in the mare. Journal of Reproduction and Fertility Supplement 56 217-226.

Allen WR 1975 The influence of fetal genotype upon endometrial cup development and PMSG and progestagen production in equids. Journal of Reproduction and Fertility Supplement 23 405-413.

Armstrong JD, Kraeling RR \& Britt JH 1988 Effects of naloxone or transient weaning on secretion of LH and prolactin in lactating sows. Journal of Reproduction and Fertility 83 301-308.

Aurich C, Schlote S, Hoppen H-O, Klug E, Hoppe H \& Aurich JE 1994 Effects of the opioid antagonist naloxone on release of luteinizing hormone in mares during the anovulatory season. Journal of Endocrinology 142 139-144.

Aurich C, Daels PF, Ball BA \& Aurich JE 1995 Effects of gonadal steroids on the opioid regulation of $\mathrm{LH}$ and prolactin release in pony mares. Journal of Endocrinology 147 195-202.

Aurich C, Lange J, Hoppen H-O \& Aurich JE 1997 Influence of melatonin and oestradiol on the opioid regulation of $\mathrm{LH}$ and prolactin release in pony mares. Journal of Endocrinology 154 241-248.

Aurich C, Parvizi N, Brunklaus D, Hoppen H-O \& Aurich JE 2000 Opioidergic and dopaminergic effects on $\mathrm{LH}$ and prolactin release in pony mares at different times of the year. Journal of Reproduction and Fertility Supplement 56 195-203.

Behrens C, Aurich JE, Klug E, Naumann H \& Hoppen H-O 1993 Inhibition of gonadotrophin release in mares during the luteal phase of the oestrous cycle by endogenous opioids. Journal of Reproduction and Fertility 98 509-514.

Cramer OM, Parker CR \& Porter JC 1979 Stimulation of dopamine release into hypophysial portal blood by administration of progesterone. Endocrinology 105 929-933.

Holtan DW, Houghton E, Silver M, Fowden AL, Ousey J \& Rossdale PD 1991 Plasma progestagens in the mare, fetus and newborn foal. Journal of Reproduction and Fertility Supplement 44 517-528.

Ireland FA, Loch WE, Worthy K \& Anthony RV 1991 Effects of bromocriptine and perphenazine on prolactin and progesterone concentrations in pregnant pony mares during late gestation. Journal of Reproduction and Fertility 92 179-186.

Johnson AL 1986 Serum concentrations of prolactin, thyroxine and triiodthyronine relative to season and the estrous cycle in the mare. Journal of Animal Science 62 1012-1020.

Lothrop CD, Henton JE, Cole BB \& Nolan HL 1987 Prolactin response to thryotrophin-releasing hormone stimulation in normal and agalactic mares. Journal of Reproduction and Fertility Supplement 35 277-280.

Nett TM, Holtan DW \& Estergreen VL 1973 Plasma estrogens in pregnant and postpartum mares. Journal of Animal Science 37 962-970.
Nett TM, Holtan DW \& Estergreen VL 1975a Levels of LH, prolactin and oestrogens in the serum of post-partum mares. Journal of Reproduction and Fertility Supplement 23 201-206.

Nett TM, Holtan DW \& Estergreen VL $1975 b$ Oestrogen LH, PMSG and prolactin in serum of pregnant mares. Journal of Reproduction and Fertility Supplement 23 457-462.

Noden PA, Oxender WD \& Hafs HD 1978 Plasma luteinizing hormone, progestogens, and estrogens in mares during gestation, parturition, and first postpartum estrus (foal estrus). American Journal of Veterinary Research 39 1965-1967.

Norusis MJ 1988 SPSS/PC+ for the IBM PC/XT/AT and PS2. Chicago: SPSS Inc.

Parvizi N \& Ellendorff F 1980 B-Endorphin alters LH secretion via the amygdala but not the hypothalamus. Nature 286 812-813.

Rowlands IW 1949 Serum gonadotrophin and ovarian activity in the pregnant mare. Journal of Endocrinology 6 184-191.

Soaje M \& Deis RP 1994 A modulatory role of endogenous opioids on prolactin secretion at the end of pregnancy in the rat. Journal of Endocrinology 140 97-102.

Soaje M \& Deis RP 1997 Opioidergic regulation of prolactin secretion during pregnancy: role of ovarian hormones. Journal of Endocrinology 155 99-106.

Stewart F \& Allen WR 1995 Comparative aspects of the evolution and function of the chorionic gonadotrophins. Reproduction in Domestic Animals 30 231-239.

Szafranska B, Weigl RM \& Tilton JE 1994 Short-term stimulation of luteinizing hormone (LH) secretion by naloxone treatment in pregnant gilts. Animal Reproduction Science 37 43-50.

Thompson DL, Reville SI \& Derrick DJ 1982 Short-term mode of secretion of equine chorionic gonadotropin and the effect of GnRH. Theriogenology 18 583-591.

Turner DD, Garcia MC \& Ginther OJ 1979 Follicular and gonadotropic changes throughout the year in pony mares. American Journal of Veterinary Research 40 1694-1700.

Whisnant CS, Kiser TE, Thompson FN \& Barb CR 1986 Influence of calf removal on the serum luteinizing hormone response to naloxone in the postpartum beef cow. Journal of Animal Science $\mathbf{6 3}$ 561-564.

Worthy K, Colquhoun K, Escreet R, Dunlop M, Renton JP \& Douglas TA 1987 Plasma prolactin concentrations in non-pregnant mares at different times of the year and in relation to events in the cycle. Journal of Reproduction and Fertility Supplement 35269 276.

Received 22 January 2001 Accepted 14 February 2001 